\title{
Comparative Analysis of the Hard Hillsides Stability by Empirical Methods and Limit Equilibrium: Case of Ultra Basic and Andesites of Mako and Marbles of Bandafassi (Senegal)
}

\author{
Déthié Sarr, Oustasse Abdoulaye Sall, Mapathé Ndiaye, Nayini Joseph Serge Lompo \\ UFR Sciences de l'Ingénieur, University of Thiès, Thiès, Sénégal \\ Email: dethie.sarr@univ-thies.sn
}

How to cite this paper: Sarr, D., Sall, O.A., Ndiaye, M. and Lompo, N.J.S. (2019) Comparative Analysis of the Hard Hillsides Stability by Empirical Methods and Limit Equilibrium: Case of Ultra Basic and Andesites of Mako and Marbles of Bandafassi (Senegal). Geomaterials, 9, 67-79.

https://doi.org/10.4236/gm.2019.93006

Received: June 10, 2019

Accepted: July 28, 2019

Published: July 31, 2019

Copyright $\odot 2019$ by author(s) and Scientific Research Publishing Inc. This work is licensed under the Creative Commons Attribution International License (CC BY 4.0).

http://creativecommons.org/licenses/by/4.0/

\begin{abstract}
The purpose of this paper is to characterize rock mass stability using basic rock mass method and to compare them. Rock mass quality and strength are determined using rock mass classification and numerical methods. The Factors of safety are calculated with the results of stereographic projection. Results show that quality of ultrabasite and marble are better than quality of andesite. The Slope Mass Ratings (SMR) show that rocks with the best quality are stable and andesite partially stable. The calculation of the factors of Safety by limit equilibrium assigns a stable state for ultrabasite and marble and instable for andesite. Calculation of Safety factor using stereographic parameters in one hand and finite element code in another shows more possibility of planar sliding along discontinuities than rock matrix failure. At last, quality of endogeneous rock mass is correlated with its stability state. The better rock mass is, the more stable the rock it is.
\end{abstract}

\section{Keywords}

Geomechanical Classification, Mako, Bandafassi, Slope Stability

\section{Introduction}

The natural slopes of rock mass can lose their stability by sliding of rock blocs along a critical surface of a fracture due to an exceeding driving force. The critical surface failure can either be an existing discontinuity or something that appears in the rock matrix after a loss of cohesiveness in rock mass. To solve this problem and avoid the disorders they bring about, we focussed our study on the stability of three slopes located in Eastern Senegal: the andesitic rock slopes of 
Mako, the ultrabasic rock slopes of Mako and the marble slopes of Bandafassi.

These areas belong to the Kedougou-Kenieba inlier and are essentially composed of endogenous rocks and sedimentary. The rock masses outcrop in the form of hills and cliffs that could sometimes be occupied by the populations. This geomorphology of the sector exposes it to risks of detachments and falls of certain stones. Besides, the mouth of Mako's mine and the setting up of the track that leads to it, constrains the populations to live in desertic areas and abrupt hillsides. This area has been the subject of many studies which have contributed to better know its geology [1] [2] [3]. The geomechanical analyses conducted on the sites concern basalts. They show by stereography, possibilities of slides [4] [5] confirmed by non zero risk. These instabilities of basaltic massifs, until recently posed the most important threat on the populations. It is therefore indispensable to know the stability state of the other types of hillsides, in order to foretell and anticipate the risks incurred by those populations in these newly equipped areas. This work will permit to understand behaviour of hills in this area and evict risk to the local people. Thus, authorities will take this into account to delineate dwelling area near hills. This analysis will be done by using the geomechanical rock mass classification indexes Rock Mass Rating (RMR), the Slope Mass Rating (SMR), Geological Strength Index (GSI) and Rock Mass Index (RMI), to determine the massifs' quality, define its stability and its strength. The hard character of the rocks studied makes structural instability occur in these massifs. The stereographic analysis and the security factor determination will be conducted by dealing with the kinematic component of the instability and will permit the verification of the relationship between that instability and the class of studied massifs.

\section{Methodology}

\subsection{Rock Mass Classification Systems}

As for the quality and behaviour analysis of hillsides in this paper, we will use Bienawski's Rock Mass Rating and the Geological Strength Index in order to define the quality and the massifs intrinsic parameters. The Rock Mass Index will permit the evaluation of the rocky massifs' strength. The Slope Mass Rating will empirically analyse their stability. These different classifications have as input parameters, the resistance of the intact rock, the presence of water, and the description of discontinuities namely the number of families, spacing, roughness of, walls alteration, filling material and elastic parameters [6].

The Rock Mass Rating (RMR): The Bienawski's classification [6] [7] goes from the principle that the behaviour of a rock mass is conditioned by the properties of the intact rock and those of discontinuities. The RMR index value is deduced from the resistance to the uniaxial compression of the sound rock $\left(A_{1}\right)$, the Rock Quality Designation (RQD) index value $\left(A_{2}\right)$, the spacing of discontinuities $\left(A_{3}\right)$, the hydraulic conditions $\left(A_{4}\right)$, the discontinuity conditions $\left(A_{5}\right)$ and the orientation of discontinuities which gives the correction coefficient $\left(A_{6}\right)$ in 
accordance with the type of work. The RMR on which the assigned score to rock mass is the sum of the five first terms scores and an adjustment one taken from the orientation of discontinuities, in relation to the considered work. The massifs to study are subdivided into different sub-areas. Each one presents a relatively homogenous character and is treated independently. The RMR index is obtained from Equation (1).

$$
\mathrm{RMR}=\sum A_{n}
$$

The adjustment value $\mathrm{A} 6$ is added mater.

The Rock Mass Index (RMI): The RMI is deduced from the uniaxial compressive strength $\left(\sigma_{c}\right)$ of the intact rock and joint parameter $\left(J_{p}\right)$ in accordance with Equation (2) where $J_{p}$ is a combined measure of the block sizes and the joints characteristics such as roughness, disturbance and alteration degree [8] [9].

$$
\mathrm{RMI}=\sigma_{c} \times J_{p}
$$

$J_{p}$ is the reduction factor deduced from the terrain geomechanical parameters. It is given by the expression.

$$
J_{p}=0.2 \times \sqrt{J_{c}} \times V_{b}^{D}
$$

$V_{b}$ is the boulder volume in cubic meters $\left(\mathrm{m}^{3}\right), J_{c}$ the joints condition factor and $D$ the rock damage factor.

$D, V_{b}$ and $J_{c}$ are given by the following relations

$$
\begin{gathered}
D=0.37 \times J_{c}^{-0.2} \\
V_{b}=\mathrm{Esp}^{2} \\
J_{c}=J_{L} \times\left(J_{R} / J_{A}\right)
\end{gathered}
$$

$J_{L}$ is the size factor representing the influence of the joint size, $J_{R}$ and $J_{A}$ are respectively coefficients depending on the roughness and the alteration, Esp is the spacing of discontinuities.

The Slope Mass Rating (SMR): This index is deduced from the basic RMR and from four correction factors, deduced from joints and slopes directions and dip but also from the excavation mode [6] [7] [8] [9] [10]. The SMR is defined in Equation (7).

$$
\begin{gathered}
\mathrm{SMR}=\mathrm{RMR}_{b}+\left(F_{1} \times F_{2} \times F_{3}\right)+F_{4} \\
F_{1}=(1-\sin \alpha)^{2} \\
F_{2}=\tan ^{2} \beta
\end{gathered}
$$

$\alpha$ evaluates the parallelism between the joint direction and the slope, $\beta$ defines the parallelism between the line of maximum gradient slope of the joint and slope. $F_{3}$ corresponds with the correction factor $A_{6}$ and $F_{4}$ is an empirical value depending on the type of excavation.

\subsection{Mechanical Properties of Rock Mass}

The identification of these parameters will be done by using the classification 
indexes of section above by calculations. They are essentially the massifs deformability module $E_{m}$, the equivalent angle of friction $\varphi_{e q}$ and the equivalent cohesion $C_{e q}$. These parameters will be then used in the limit equilibrium method to determine the safety factor. Because massifs are fractured, all parameters are defined using rock description and field characterization. These properties are integrated in rock mass indexes and take into account effect of joints in the rock.

Rock mass parameters determination: The massif deformation modulus $\left(E_{m}, \mathrm{Gpa}\right.$ ) will be determined from the RMR classification according to Equation (10) and Equation (11).

$$
\begin{aligned}
& \text { For } \quad \mathrm{RMR}>50 \\
& E_{m}=2 \mathrm{RMR}-100 \\
& \text { For } \quad \mathrm{RMR}<50 \\
& E_{m}=10^{(\mathrm{RMR}-10) / 40}
\end{aligned}
$$

The equivalent cohesion and the angle of friction of the rocky massif from the RMR value are given by Equation (12) and Equation (13).

$$
\begin{gathered}
C_{e q}=5 \mathrm{RMR} \\
\varphi_{e q}=0.5 \mathrm{RMR}+8.3 \pm 7.3
\end{gathered}
$$

\subsection{Stability}

The stability analysis of massif slopes will be done first by using the stereographic projection to define the possible types of landslide on which the limit equilibrium method will be applied in order to define safety factors. The geotechnical parameters will be deduced from the classification indexes. The discontinuity is supposed to occur using one or more predefined plans. These calculation methods assume that the terrain behaves like a solid obeying to shear fracture classical laws. The safety factor calculation is done either directly or in an iterative way.

The Stereographic Analysis: The stereographic analysis will be conducted by using the method described by Denis and al (2002). This method has the advantage of only using the discontinuity plans, the rocky slope and the bedrock. Four criteria will be analysed. First, "breakthrough" of the joints intersection line; second, "meeting" for that intersection line; third, "breakthrough" for the joints mines of relative dip of slope; at last, "clearance" between the joints intersection lines and those of relative dip of slope that break through.

Determination of Security Factor (FS): For planar sliding instability, the safety factor is determined by the Equation (14).

$$
\mathrm{FS}=\tan \varphi / \tan \alpha
$$

$\varphi$ being the internal angle of friction, equivalent of the rock mass and $\alpha$ the dip of the sliding plan.

For the slides along the intersection line of two planes of discontinuities, the safety factor calculation depends on the angle between the two joints, the inter- 
section line dip $\alpha$ and the dip $\kappa$ of the bisector plan when referring to joint with minimum dip. The security factor is calculated by using the Equation (15).

$$
\mathrm{FS}=(\sin \kappa / \sin (\xi / 2)) /(\tan \varphi / \tan \alpha)
$$

The angles $\xi$ and $K$ are determined in a stereographic representation. The circular ruptures concern the intensely fractured rocks which are consequently considered as granular media. The safety factors will be defined by using soils mechanical methods. The calculated classification indexes allow homogenization of massifs and consider matrix failure.

The Fellenius method which admits that inter buckets external forces are equal. This case is modelled by the function:

$$
\mathrm{FS}_{\text {fallenius }}=\left[\sum_{1}^{n}\left(c^{\prime} \Delta x_{i} / \cos \alpha_{i}+\left(W_{i} \cos \alpha_{i}-u_{i} \Delta x_{i} / \cos \alpha_{i}\right) \tan \varphi^{\prime}\right)\right] / \sum_{1}^{n} W_{i} \sin \alpha_{i}
$$

The Bishop method which admits that only the horizontal components of external inter buckets forces are equal. the Factor of Safety is defined using the following Equation (17).

$$
\mathrm{FS}_{\text {Bishop }}=\left(\sum_{1}^{n}\left(c_{i}^{\prime} \Delta x+\left(W_{i}-u_{i} \Delta x_{i}\right) \tan \varphi_{i}^{\prime}\right) / M_{i}\right) /\left(\sum_{1}^{n} W_{i} \sin \alpha_{i}\right)
$$

with,

$$
M_{i}=\cos \alpha_{i}+\left(\tan \phi_{i}^{\prime} \sin \alpha_{i}\right) / \mathrm{FS}
$$

The Mako area is geologically well studied but geomechanical aspects are not. The defined indexes of rock masses will be compared. The safety factors calculated by considering joint failure and rock matrix failure will also be compared to determine the most possible type. The possible link between Indexes of rock masses and safety factors will be examined.

\section{Results Analysis}

\subsection{Evaluation of the Classification Indexes}

The RMR determination: For the RMR index determination it is necessary to know the uniaxial compression strength, the rock's RQD, the spacing of discontinuities and the state of their walls surfaces, and the massif's hydric condition. A score is affected to each of these parameters. The sum of these different scores gives to each massif an overall score which corresponds with the RMR index. All these parameters allow the assignment of the RMR index to the massif from the different massifs in the table below (Table 1). For the Marble of Bandafassi, the RMR index is 71 (Class of good quality rocks, Class II) during dry season and 67 (Class II) during the raining season. For Mako's Ultrabasites, RMR index is 82 (class of very good quality rocks, Class I) at dry season and 67 (Class II) during raining season corresponding with good rock mass. For Mako's Andesites, RMR index is 41 (Fair quality rocks, Class III) at dry season and 26 (Class IV) at raining season which corresponds with poor rock mass. According to RMR classification ultrabasite and marble are best quality than andesite massif. 
Table 1. Summary of massifs classes by the RMR.

\begin{tabular}{cccc}
\hline Parameters & Marble & Ultrabasite & Andesite \\
\hline Rc (MPa) & $100-250$ & $50-100$ & $50-100$ \\
$A_{1}$ & 12 & 7 & 7 \\
RQD & 97 & 94 & 12 \\
$A_{2}$ & 20 & 20 & 3 \\
Spacing (mm) & $600-2000$ & $600-2000$ & $200-600$ \\
$A_{3}$ & 15 & 15 & 10
\end{tabular}

Nature of discontinuity 1.i, $1-5 \mathrm{~mm}$, r.d, e.r, l.a. $1<1 \mathrm{~m}$, e.cn.r, t.r, t.a, $\quad$ l.i, $>5 \mathrm{~mm}$, r.d, e.l.r, t.a,

$A_{4}$

Water contain

$$
A_{5}
$$

$\operatorname{RMR}\left(\sum A\right)_{\mathrm{dry}}$

Quality $_{\text {dry }}$

$\mathrm{RMR}_{\text {debiting }}$
9

Dry

Debiting

15

71

Good

56
25

Dry

Debiting

15

82

Very Good

67
Dry

Debiting

15

41

Fair

26

(li = Indefinite length; $r . d=$ Rough discontinuity; e.r = Rough wall; $1 . \mathrm{a}=$ slightly altered; e.cn. $\mathrm{r}=$ Non-rough (soft) continuous wall; t.r $=$ Very rough; t.a $=$ Very altered; e.l.r $=$ Slightly rough wall $)$

Determination of the Geological Strength Index (GSI): The indexes obtained are summarised in Table 2. They classify marbles among good quality rocks, with a GSI between 50 and 60. Ultrabasites are fair with a GSI between 50 and 55 and andesites correspond with poor quality rock masses since it's values are 20 and 30. Therefore, these hard rock masses are from poor to good classes. Andesite and Ultrabasite are more fractured than marble because the Mako area has suffered more orogenesis than. Diale-Dalema.

Determination of the Rock Mass Index (RMI): The Rock Mass Index is used to estimate the rocky massif's strength. The RMI system is calculated from the Equation (2) which makes the strength intervene into the compression of the intact rock, obtained with the Sclerometer and the Joint parameter $J_{p}$. The results (Table 3), give RMI values largely superior to 10 for ultrabasic rocks and just superior to 10 for marble. These two massifs are then of very high resistance. For andesites, the RMI is between 1 and 10 which characterises high resistance massifs.

These strength values stick well with the petrographic nature of rocks. That GSI classification is among the four classifications used, the unique for which the marble's massif admits a better quality than that of ultrabasite, even if they are at least of a good quality. That would relate to the very limited number of parameters which happen into the calculation in one hand. In another hand, tectonic of kedougou leads less strength quality to older massif's. That rock masses are affected by all orogenesis of the area. 
Table 2. Summary of massifs classes by the GSI.

\begin{tabular}{cccc}
\hline Parameters & Marble & Ultrabasite & Andesite \\
\hline$R_{r}$ & Slightly rough & Very rough & Slightly rough \\
& 3 & 6 & 3 \\
$R_{W}$ & Slightly weathered & Highly weathered & Highly weathered \\
& 5 & 1 & 1 \\
$R_{f}$ & Hard infiling $<5 \mathrm{~mm}$ & None & Hard \\
$J_{V}$ & 4 & 6 & 2 \\
SCR & 4.38 & 6.7 & 39.4 \\
SR & 12 & 13 & 6 \\
GSI & 68 & 58 & 22 \\
Quality & $55-60$ & $50-55$ & $20-30$ \\
\hline
\end{tabular}

( $R_{r}=$ Roughness coefficient; $R_{w}=$ Joint wall alteration; $R_{f}=$ disontinuity filling; $J_{V}=$ volumetric density; SCR = Surface condition rating; $\mathrm{SR}=$ Structure rating).

Table 3. Summary of the RMI values.

\begin{tabular}{ccccccc}
\hline \multicolumn{2}{c}{ Parameters } & $V_{b}$ & $J_{c}$ & $D$ & $J_{P}$ & RMI \\
\hline \multirow{5}{*}{ Ultrabasite } & P1 & 3.581 & 2 & 0.32 & 0.427 & 35.007 \\
& P2 & 0.343 & 1.5 & 0.32 & 0.201 & 16.481 \\
& P3 & 0.055 & 2 & 0.45 & 0.09 & 10.901 \\
& P4 & 0.125 & 1.5 & 0.341 & 0.120 & 9.889 \\
& P1 & 0.091 & 2.25 & 0.314 & 0.141 & 7.102 \\
& P2 2 & $27 \mathrm{E}-6$ & 0.263 & 0.023 & 0.08 & 4.03 \\
& P3 & 0.0176 & 1.5 & 0.215 & 0.102 & 5.135 \\
& P1 & 0.512 & 0.375 & 0.45 & 0.09 & 10.35 \\
Marbre & P2 & 0.166 & 0.375 & 0.45 & 0.054 & 6.21 \\
& P3 & 0.512 & 0.375 & 0.45 & 0.09 & 10.35 \\
\hline
\end{tabular}

Determination of the Slope Mass Rating (SMR): This classification results are presented in Table 4. The obtained values are superior or equal to 77 for the marble. That classifies them in category II corresponding with stable rock masses. For ultrabasite rocks, the SMR indexes are superior to 89 which classify them in the category of very good quality rocks, therefore, completely stable ones. The andesite shows the weakest SMR values, around 52, corresponding with the fair quality rock masses, therefore partially stable. The presence of water that expose more these rock masses to instabilities, materialized here by the drop of the SMR index. In that case, the drop does not make a change in the massif's class, and fractures remain occasional, as far as ultrabasites are concerned. However, in the presence of water, andesites move from fair quality rock to poor one with intense fractures phenomena. It is then obvious that water plays an 
Table 4. Summary of the indications given by the SMR.

\begin{tabular}{ccccccccccc}
\hline & $F_{1}$ & $F_{2}$ & $F_{3}$ & $F_{4}$ & $\begin{array}{c}\text { RMR } \\
(\text { dry })\end{array}$ & $\begin{array}{c}\text { RMR } \\
\text { (wet) }\end{array}$ & $\begin{array}{c}\text { SMR } \\
\text { (dry) }\end{array}$ & $\begin{array}{c}\text { SMR } \\
\text { (wet) }\end{array}$ & Class & Stabiliy state \\
\hline P1 & 0.15 & 1 & -60 & 15 & & & 77 & 62 & I/II & \\
P2 & 0.15 & 1 & -60 & 15 & 71 & 56 & 77 & 62 & I/II & Stable \\
P3 & 0.4 & 0.15 & -60 & 15 & & & 82 & 67.4 & I & \\
& & & & & & Ultrabasite & & & & \\
P1 & 0.15 & 0.85 & -60 & 15 & & & 89 & 74 & I & \\
P2 & 0.15 & 1 & 0 & 15 & & & 97 & 82 & I & Stable \\
P3 & 0.15 & 1 & -25 & 15 & & & 93 & 78 & I & \\
P4 & 0.15 & 1 & -6 & 15 & & & 96 & 81 & I & \\
& & & & & & Andesite & & & & \\
P1 & 0.15 & 1 & -25 & 15 & & & 52 & 37 & III/IV & Partially \\
P2 & 0.15 & 1 & -25 & 15 & 41 & 26 & 52 & 37 & III/IV & stable /Instable \\
P3 & 0.15 & 1 & -25 & 15 & & & 52 & 37 & III/IV & \\
\hline
\end{tabular}

important role in the rock masses stability. We can note that seasons change is also very important in the massifs stability, favouring slides during rainy periods.

According to massif classification, it appears that rock mass quality is correlable with state of stability. More good $i$ is the rock mass quality, the more stable it is.

\subsection{Representation of the Different Stereograms}

The orientations of the different families of joint and the slope are:

for Ultrabasic discontinuities are: P1 (N174-44NE), P2 (N130-40NE), P3 (N70-60SE), P4 (N84-65SE), Slope (N40-60SE);

for andesite: P1 (166-80NE), P2 (N116-80NE), P3 (N42-54SE), Slope (N84-56SE);

for marble: P1 (N90-05N), P2 (N170-76NE), P3 (N42-66NW), Slope (N118-86NE).

The Stereogram of Figure 1(a) shows possibilities of dihedral sliding whose lines are the discontinuities intersection lines D1 (P1, P3); D2 (P1, P4) and D3 (P2, P4), which form dihedrons with the slope they break through, except D4 (P3, P4). The ultrabasite massif shows possibilities of slides on different joint intersection lines taken in pairs. Possibilities of movements on P1 and P2 are also noted. The stereographic projection of Bandafassi's marble discontinuities is represented below on Figure 1(b). It shows dihedral sliding possibilities, which means we may have a slide on two planes whose discontinuities intersection's line, when analysed, form with the slope it breaks through. Here, the intersection lines orientation between analysed discontinuities D5 (P2, P3) and D6 (P1, P3), 


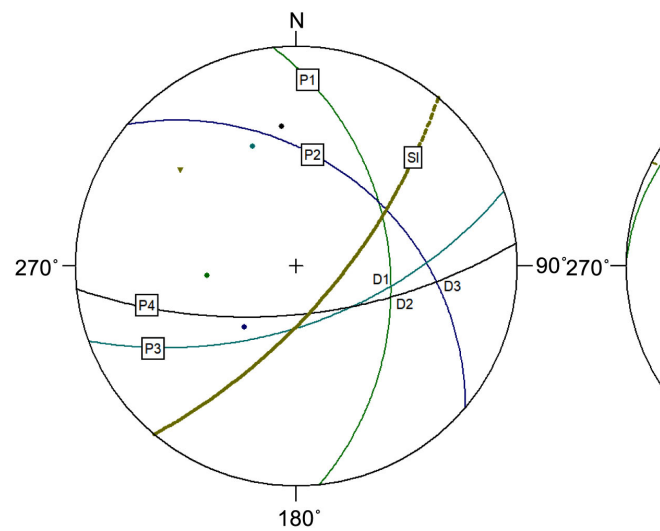

(a)

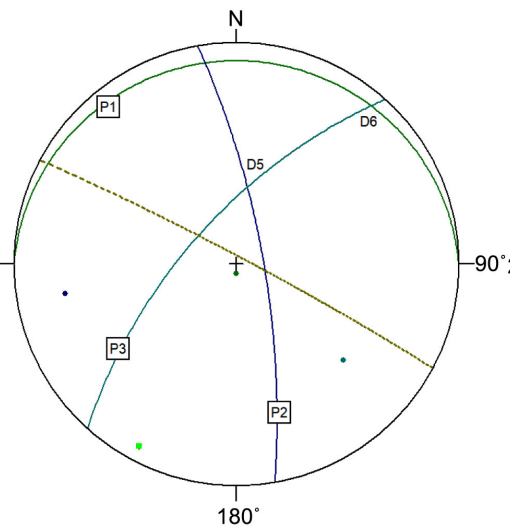

(b)

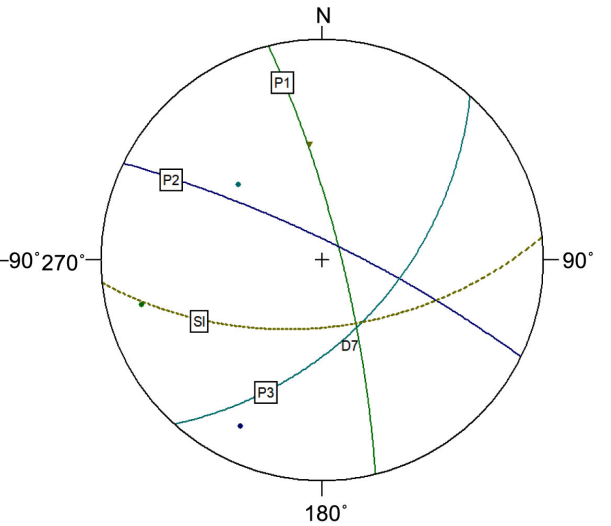

(c)

Figure 1. Stereographic representation of ((a) Mako's ultrabasite; (b) Bandafassi's marble; (c) Mako's andesite).

are in the same directions as that of the rock slope. Besides, they intersect the rock slope under the bedrock plan. The "breakthrough" of the discontinuities intersection lines analysed is also checked. It is also possible to have a movement following the plan P1. The stereographic projection of Mako's andesite discontinuities represented on Figure 1(c) shows a single possibility of dihedral slides, following the intersection line of the two joints. The orientation of the intersection line between the analysed discontinuities D7 (P1, P3), is the same as that of the rock slope. The intersection line between these two discontinuities intersects the rock slope under the bedrock plan by breaking it through, but this latter is not cleared. As for the other intersections, they are localised under the andesite's rock slope.

In conclusion, all the slopes studied, show possibilities of dihedral slide dominating, and sometimes associated to planar slides. These movements take place in the direction of the excavation's dip, and they are possible since the criteria of "breakthrough", "meeting" and "cleared", defined by Denis and Al. (2002), are confirmed. Thus, the andesite and ultrasite massifs of Mako, as well as the marbles of Bandafassi, present risks of instabilities.

\subsection{Calculation of Stability Using Stereographic Results}

Table 5 gives a summary of the parameters checking massifs stabilities by using stereographic results. The minimum security coefficients for the ultrabasite massifs of Mako are 1.20 for planar sliding and 2.22 for dihedral sliding. Based on the results obtained, we note that the security factor is fairly high for the two types of slides. The ultrabasite rock mass of Mako is then stable. However, this stability is quite limited in the case of planar sliding where safety factors are very close to the limit value. As far as the marble of Bandafassi is concerned, we note in the case of dihedron (P1, P3), safety factors superior to 17 and showing evidence that it is very stable. For dihedron (P2, P3) where the safety factor is limited, instabilities occur when this dihedron is exposed. The planar sliding also seems to be present and favoured, even though they are unlikely to produce happened with a safety factor superior to 11 . As for the massif of andesitic rocks, 
Table 5. Summary of geomechanic's parameters.

\begin{tabular}{|c|c|c|c|c|c|}
\hline \multicolumn{6}{|c|}{ Ultrabasite of Mako } \\
\hline Joints & $\kappa$ & $\varphi$ & $\xi$ & $\alpha$ & FS \\
\hline $\mathrm{P} 2, \mathrm{P} 4$ & 87.2 & 49.3 & 94.4 & 24.7 & 3.4 \\
\hline P1, P3 & 73.8 & 49.3 & 59.7 & 42.4 & 2.4 \\
\hline $\mathrm{P} 1, \mathrm{P} 4$ & 80.35 & 49.3 & 72.7 & 41.12 & 2.2 \\
\hline $\mathrm{P} 2$ & & 49.3 & & 40 & 1.3 \\
\hline P1 & & 49.3 & & 44 & 1.2 \\
\hline \multicolumn{6}{|c|}{ Andesite of Mako } \\
\hline Joints & $\kappa$ & $\varphi$ & $\xi$ & $\alpha$ & FS \\
\hline P1, P3 & 79 & 28.8 & 58 & 50.4 & 0.9 \\
\hline \multicolumn{6}{|c|}{ Marble of Bandafassi } \\
\hline Joints & $\kappa$ & $\varphi$ & $\xi$ & $\alpha$ & FS \\
\hline P2, P3 & 81.65 & 45.8 & 63.3 & 63.4 & 1.0 \\
\hline P1, P3 & 36.35 & 45.8 & 62.7 & 3.8 & 17.6 \\
\hline P1 & & 45.8 & & 5 & 11.1 \\
\hline
\end{tabular}

we have a possibility of dihedron, with a very poor security factor of 0.9. The massif of Mako's andesite is then structurally unstable. This instability is related to joints in the massif and it is dynamic, due to the morphology sometimes ondulating of discontinuities.

\subsection{Calculation of Stability Using Plaxis Finite Element Modelling}

Total displacements given by Plaxis finite element code are higher for marble with $8.33 \mathrm{~mm}$ displacement (Figure 2) than ultrabasite with $237.06 \mu \mathrm{m}$ displacement (Figure 3) and andesite with $9.33 \mu \mathrm{m}$ displacement (Figure 4). They are not directly correlable with the state stability of rock mass but with the slope geometry and slope high. For andesite $(F S=1.21)$ and ultrabasite $(F S=1.95)$, the rock matrix failure is relatively impossible even if it is questionable for andesite. However, marble $(\mathrm{FS}<1)$ is instable because of its slope close to the vertical.

According to slopes, andesite and ultrabasite justified possible finite element geometry. That explains their rock matrix stability. For marble slope, very close of vertical, finite element method stability is difficultly applicable. the instability of marble rock matrix is on one part caused by that slope angle.

\section{Conclusion}

This work has been achieved with the accumulation of field and laboratory data, necessary to the use of geomechanical classifications, stereographic analyses and limited equilibrium calculation. The results obtained have allowed observing instability possibilities of the blocks limited by discontinuities. The RMR geomechanical classification, for the studied slopes, gives rocks which quality depends 


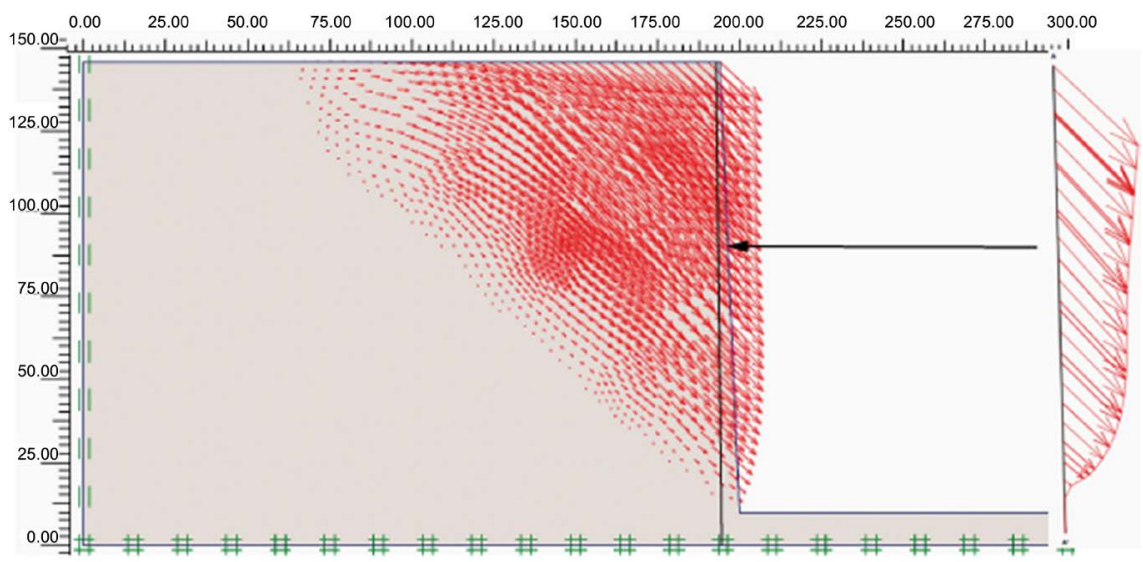

Figure 2. Finite element modelling result of Bandafassi's marbles (Total displacement Utot (Extreme displacement Utot $=8.52 \mathrm{E}-3 \mathrm{~m} /$ at vertical of top point of slope $=8.52 \mathrm{E}-3$ m)).

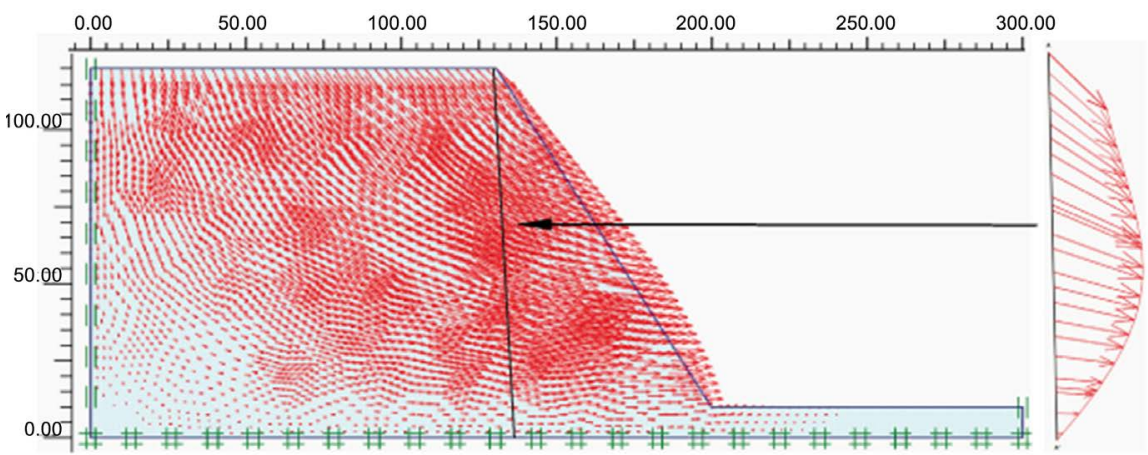

Figure 3. Finite element modelling result of Mako's ultrabasite (Total displacement Utot (Extreme displacement Utot $=237.06 \mathrm{E}-6 \mathrm{~m} /$ at vertical of top point of slope $=212.73 \mathrm{E}-6$ $\mathrm{m}))$.

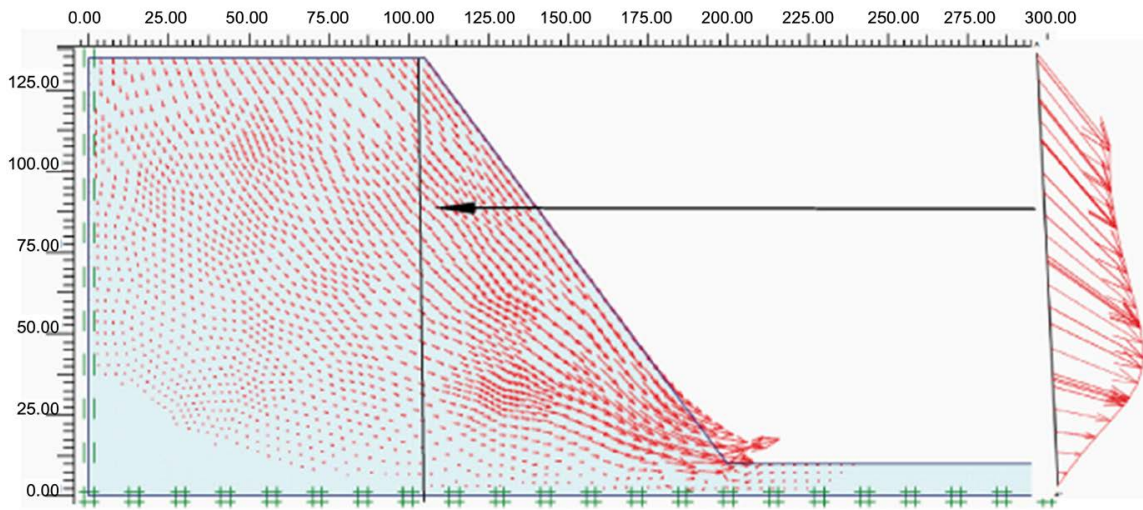

Figure 4. Finite element modelling result of Mako's andesite (Total displacement Utot (Extreme displacement Utot $=9.33 \mathrm{E}-6 \mathrm{~m} /$ at vertical of top point of slope $=1.62 \mathrm{E}-6)$ ).

on their waterborne and hydraulic state. In the presence of water, the massifs of ultrabasics, of andesites and of marbles lose their quality. The GSI classification shows qualities that may be different from those obtained by the RMR. These differences are explained by the fact that the parameters which come into play, 
in the two classifications, are different. The rock mass strength analyzed with the RMI is very high for marbles and ultrabasics, whereas they are high for the andesite massif. Thus, according to the geomechanical classifications, the massifs of marble and ultrabasite are better than the massif of andesite. That is confirmed by SMR index which shows that ultrabasite and marble are stable when andesite is partially stable to unstable according to waterborne and hydraulic state. For these endogeneous rock mass, their stabilities are also correlated with their strength defined by RMI. The stereographic analysis allowed the observation of composed failure, either following joints or their intersection lines. For ultrabasite, the identified slides remain impossible, since the corresponding safety factors are highly superior to 1 . However, planar sliding must be treated with respect since the values of the safety factors are inferior to 1.5 . The slopes studied for the marble on the other hand are hyper stable with a safety factor superior to 11.1 except the dihedron (P2, P3) which is limit. The andesite massif remains to be instable since the safety factor for dihedron is inferior to 1 . Taking account safety factors using stereographic study and the one PLAXIS, the rock matrix failure is relatively impossible. The failure occurs along discontinuities. Definitely, the massif's quality following their slopes, is correlatable to its stability. Since ultrabasites and the good quality marble have safety factors ensuring their stability, unlike the andesite, of fair to poor quality, which is unstable with a Safety factor inferior to 1 . So instability of these hard massifs occurs essentially following to discontinuities than rock matrix. So use of finite element modelling will be done with respect. Boulders having been found on the slopes, a probabilistic analysis seems necessary to better understand the evolution of these instabilities. This study will also be extended to other rocks to draw a general model.

\section{Acknowledgements}

Authors would acknowledge to Profesor Papa Malick Ngom of Cheikh Anta Diop University of Dakar for the review of this paper.

\section{Conflicts of Interest}

The authors declare no conflicts of interest regarding the publication of this paper.

\section{References}

[1] Dia, A. (1988) caracteres et signification des complexes magmatiques et metamorphiques du secteur de sandikounda-laminia (Nord de la boutonnière de Kédoegou; Est du Sénégal) Un modèle géodynamique du Birimien de l'Afrique de l'Ouest. Thèse de Doctorat d'état, Université Cheikh Anta Diop de Dakar (UCAD).

[2] Ngom, P.M. (1995) Caractérisation de la croûte birimienne dans les parties centrale et méridionale du supergroupe de' Mako. Implications géochimiques et pétrogénétique. Thèse de Doctorat d'Etat, Université Cheikh Anta Diop de Dakar (UCAD).

[3] Ndiaye, P.M. (1994) Evolution au proterozoique inferieur de la region est-saraya 
(craton de l'afrique de l'ouest, senegal-mali). Tourmalinisations, alterations hydrothermales et mineralisations associees. Thèse de Doctorat d'Etat, Université Cheikh Anta Diop de Dakar (UCAD).

[4] Sarr, D., Fall, M., Ngom, P.M. and Ndiaye, M. (2011) Mechanical Behavior of Pillow Lavas in Mako Supergroup: Case of South Mako Hill. International Journal of Geosciences, 4, 640-647. https://doi.org/10.4236/ijg.2011.24065

[5] Sarr, D., Fall, M., Ngom, P.M. and Gueye, M. (2013) New Approach of Geomechanical Properties by Scale Effect and Fractal Analysis in the Kedougou-Kenieba Inlier (Senegal-West Africa). Geomaterials, 3, 145-155. https://doi.org/10.4236/gm.2013.34019

[6] Bieniawski, Z.T. (1973) Engineering Classification of Jointed Rock Masses. Transaction of the South African Institution of Civil Engineers, 15, 335-344.

[7] Bieniawski, Z.T. (1989) Engineering Rock Mass Classification. A Complete Manual for Engineers and Geologists in Mining, Civil and Petroleum Engineering. Wiley Interscience, Hoboken, 51-68.

[8] Palmström, A. (1995) RMI-A System for Characterizing Rock Mass Strength for Use in Rock Engineering. Journal of Rock Mechanics and Tunnelling Technology, 1, 69-108. https://doi.org/10.1016/0886-7798(96)00015-6

[9] Palmström, A. (1996) The Rock Mass Index (RMI) Applied in Rock Mechanics and Rock Engineering. Journal of Rock Mechanics and Tunnelling Technology, 11, 1-40. https://doi.org/10.1016/0886-7798(96)00015-6

[10] Romana, M.R. (1993) A Geomechanical Classification for Slopes: Slope Mass Rating. In: Hudson, J.A., Ed., Comprehensive Rock Engineering, Pergamon Press, Oxford, New York, Seoul, Volume 3, 575-600. https://doi.org/10.1016/B978-0-08-042066-0.50029-X 